The Working Group on the 1972 General Physics Conference has drafted proposals representing the most widely accepted views on this second General Physics Conference of the Society. At its meeting on 25 September 1970 the Conference Committee discussed and approved this outline which will be submitted to the Executive Committee so that detailed planning can start soon. The proposals and comments are summarized below.

\section{General Scope and Programme}

A four-day conference of the Florence-type is proposed, with general talks by invited speakers forming an important part of the programme. The main emphasis should rest on the interaction of physics with other sciences and cultural activities. The suggested title 'Trends in the Development of Modern Physics' may yet be modified by the Programme Committee of the Conference. An exhibition could be organized to take place during the Conference.

Four mornings would be devoted to General Sessions, each with a maximum of three lectures, covering subjects of current interest in physics and general topics such as modern computational methods, experimental techniques and data analysis. Two or three lectures should deal with technology concerning, for instance, lasers, superconductors and imaging processes.

On three afternoons parallel subsessions would be held by EPS Divisions. These Divisional Sessions could each consist of invited lectures and of contributed papers. The programmes worked out by the Divisions in consultation with the Interdivisional Group on Computational Physics and the EPS Advisory Committees on Applied Physics and Physics in Industry and on Physics in Society are

\title{
Plans for the 1972 EPS General Conference
}

\section{Wiesbaden, 3-6 October 1972}

to be submitted to the Conference Programme Committee.

Two evening sessions, each with a maximum of two lectures and organized with the aid of the appropriate Advisory Committee, are to deal with subjects such as Physics and Society, Physics and Education, Physics and Industry. One of these sessions may be made a public one.

One afternoon will be reserved for the EPS General Assembly, and on a subsequent day a short Information Meeting will be held preceding a Divisional Session. This meeting, open to all participants, will be given a report by the President of the EPS on the General Assembly and on the aims and activities of the Society, and will end with a question period. Members of the Executive Committee, as well as Chairmen of Divisions and Advisory Committees will be present. In general, the timetable of the Conference should not be too tight and some free time should be allowed for.

\section{Organization}

This should be in the hands of an Organizing Committee consisting of a Local Committee from the host organization and including one official EPS delegate, and a Programme Committee made up of delegates from each EPS Division, from the appropriate Advisory Committees and the Interdivisional Group on Computational Physics and including at least one member of the EPS Conference Committee. The Chairman of the Organizing Committee will keep the Conference Committee informed about the progress of preparations.

\section{Fees}

A basic fee, to be determined by the host organization, is proposed for payment by participants who are Individual Ordinary Members of the EPS. A reasonable figure for this may be Sw. fr. 60.- This basic fee would be augmented by Sw. fr. 20.- for members of National Societies adhering to EPS, and by Sw. fr. 40.- for all other participants.

\section{Young Physicists}

To encourage the participation by young physicists the provision of fellowships, as in the case of the Florence Conference, would be desirable, and the Local Committee should be asked to secure cheap accommodation for young participants. Contributed papers (10-15 minutes) might be admitted for the afternoon sessions. The abstracts of all accepted contributed papers would be printed in the Proceedings, whereas a lastminute selection would be made of papers that are to be presented at the sessions.

\section{Venue and Date}

The offer of the German Physical Society (Deutsche Physikalische Gesellschaft e.V.) to organize the Conference at Wiesbaden was acceptod by the Conference Committee. The date proposed is 3-6 October 1972, which will not interfere with the IUPAP General Assembly, scheduled for September 1972 in Washington, D.C.

The Conference Committee also expressed the hope that the venue for the 1975 Conference might be in Eastern Europe. 